\title{
Identificação de oportunidades de pesquisa a partir de um levantamento da implantação da produção enxuta em empresas do Brasil e do exterior
}

\author{
Identification of research opportunities based on a \\ survey on lean production implementation conducted \\ in Brazilian and foreign companies
}

\author{
Tarcisio Abreu Saurin ${ }^{1}$ \\ José Luis Duarte Ribeiro' \\ Giuliano Almeida Marodin ${ }^{1}$
}

\begin{abstract}
Resumo: Este artigo apresenta um levantamento do processo de implantação da Produção Enxuta (PE) em 47 empresas do Brasil e do exterior. Entre os principais resultados, o levantamento revelou que: os temas de maior interesse em ampliar conhecimentos são a cultura organizacional enxuta e o mapeamento do fluxo de valor; os principais motivos para adotar a PE são a necessidade de melhorar a competitividade e a adequação da PE ao combate de problemas críticos da produção; as principais dificuldades na implantação da PE são a resistência das pessoas e a dificuldade na adaptação de conceitos e práticas; as práticas mais utilizadas são a padronização do trabalho e o gerenciamento visual; a produção puxada é a prática prioritária no momento. Os resultados deste levantamento, aliados a observações realizadas durante visitas em algumas das empresas, permitiram a identificação de necessidades e oportunidades para pesquisas sobre a implantação da PE, as quais são sumarizadas no final do artigo.
\end{abstract}

Palavras-chave: Produção enxuta. Questionário. Avaliação de empresas.

\begin{abstract}
This paper presents a survey on the lean production (LP) implementation process in 47 Brazilian and foreign companies. Among the main results, the survey pointed out that the respondents are mostly interested in learning about lean organizational culture and value stream mapping. The main drivers for adopting LP are improving competitiveness and the fact that LP is adequate to solve critical production problems. People resistance to changes and difficulties to adapt concepts and practices are the main difficulties during LP implementation. The most frequently used practices are work standardization and visual management. Pull production implementation is the practice of highest priority. The results of this survey, along with the observation data collected during visits to some of the investigated companies, permitted the identification of research opportunities on LP implementation, which are summarized at the end of this article.
\end{abstract}

Keywords: Lean production. Questionnaires. Organizational assessment.

\section{Introdução}

Embora a produção enxuta (PE) continue sendo disseminada no meio empresarial, pouco é conhecido a respeito dos detalhes, maturidade e contexto da sua implantação nas empresas brasileiras e estrangeiras. Uma pesquisa realizada pelo Lean Enterprise Institute (2007) junto a 2440 respondentes de vários países, concluiu que $11 \%$ das empresas estavam apenas planejando adotar a PE, enquanto $48 \%$ estavam em estágios muito iniciais de implantação, contemplando apenas algumas áreas piloto.
De fato, a implantação da PE é complexa, demorada e requer a alocação de uma quantidade substancial de recursos por parte de empresas (LIAN; VAN LANDEGHEM, 2007). Como resultado desta dificuldade de implantação, Baker (2002) e Sohal e Eggleston (1994), com base em pesquisas realizadas em diferentes países, concluíram que menos de 10\% das empresas que iniciaram um projeto de implantação alcançaram maturidade em seus sistemas enxutos.

Diversos estudos, normalmente adotando a survey como estratégia de pesquisa, têm identificado fatores

\footnotetext{
1 Programa de Pós-Graduação em Engenharia de Produção e Transportes da Universidade Federal do Rio Grande do Sul PPGEP/UFRGS, Av. Osvaldo Aranha, 99, 5ª andar, CEP 90035-190, Porto Alegre - RS, Brasil, E-mails: saurin@ufrgs.br; ribeiro@producao.ufrgs.br; zmarodin@terra.com.br
} 
importantes para a eficácia das implementações da PE. Cua, McKone e Schroeder (2001) concluíram que a implantação conjunta de práticas associadas à gestão da qualidade total, just-in-time e manutenção produtiva total, produz resultados melhores do que aqueles obtidos quando cada prática é aplicada isoladamente. Já as pesquisas realizadas por Golhar, Stamm e Smith (1990), White (1993) e White, Pearson e Wilson (1999) detectaram que fatores importantes na implantação da PE são o tempo de experiência com as práticas (quanto mais longo, melhores os resultados), o tipo de processo produtivo (processos repetitivos e em linha facilitam a implantação e geram maiores ganhos em comparação a ambientes job-shop) e o porte da empresa. Em relação ao porte, uma das conclusões foi que, nos Estados Unidos, as grandes empresas estão em estágio mais avançado de implantação das práticas enxutas e as usam há mais tempo em comparação às pequenas empresas, com exceção da prática multifuncionalidade da mão de obra (WHITE; PEARSON; WILSON, 1999). Outros fatores identificados em estudos anteriores foram os investimentos na infraestrutura de apoio à manufatura (SORIANO-MEIER; FORRESTER, 2002) e a existência de sistemas de incentivos a gerentes e operários (KOH; SIM; KILLOUGH, 2004). Por outro lado, Shah e Ward (2002) concluíram que fatores de pouca influência são a idade da planta e o grau de sindicalização dos operadores.

Com base em tais estudos, fica claro que o sucesso da implantação da PE depende das particularidades de cada empresa, conforme as inter-relações entre os diversos fatores cujo impacto já é conhecido. Lewis (2000) reforça que as trajetórias encontradas pelas empresas para implantar a PE são únicas na maioria dos casos, pois há necessidade de adaptações para cada contexto organizacional, tecnológico e ambiente externo à organização.

Entretanto, há poucos estudos que aprofundem a compreensão qualitativa dos fatores e suas interfaces, $o$ que pode ser decorrente de causas como as seguintes: a) o desejo de muitas empresas em manter sigilo de seus dados; b) o fato de que muitas das implantações vêm sendo feitas com apoio de consultorias, o que normalmente não resulta na divulgação destes trabalhos no meio acadêmico; c) muitas das principais aplicações da PE ocorrem em empresas de médio e grande porte, o que tende a tornar mais trabalhoso o levantamento de dados; d) os três fatores anteriores dificultam o uso de métodos de pesquisa que permitiriam o aprofundamento qualitativo (por exemplo, estudos de caso), o que induz ao uso extensivo de surveys; e e) a simplificação demasiada de alguns modelos da PE (por exemplo, a casa do Sistema Toyota de Produção proposta por LIKER, 2004), que não explicitam a natureza das interfaces entre os diversos elementos do sistema enxuto.
Deste modo, considerando a necessidade de aprofundar o conhecimento acerca da implantação da PE, pesquisadores da equipe responsável por este trabalho estabeleceram um grupo de troca de experiências acerca do assunto, envolvendo gerentes de empresas que vinham adotando a PE em maior ou menor grau. No âmbito de tal grupo, foi desenvolvida uma pesquisa exploratória. Essa pesquisa utilizou um questionário para levantar informações acerca do perfil dos participantes, em sua maioria fortemente envolvidos com a implantação da PE em suas empresas, bem como informações acerca do processo de implantação da PE nas respectivas empresas, tais como as principais dificuldades e práticas enxutas prioritárias. Paralelamente a essa iniciativa, o mesmo questionário foi submetido a respondentes não envolvidos no grupo de troca de experiências, cujas empresas possuíam a adoção da PE como característica em comum.

Os resultados da aplicação desse questionário, somados a observações realizadas durante visitas às empresas participantes do grupo de troca de experiências, contribuíram para a identificação de necessidades e oportunidades de pesquisas acerca da implantação da $\mathrm{PE}$, as quais podem ser interpretadas como uma base para o estabelecimento de questões de pesquisa que ainda não foram investigadas, especialmente no contexto brasileiro. Além disso, apesar da amostra ter sido constituída por conveniência, sem a intenção de ser estatisticamente representativa das empresas que adotam a PE no Brasil e no exterior, os resultados obtidos constituem uma base de comparação para pesquisas futuras que visem avaliar a implantação da PE.

\section{Método de pesquisa}

\subsection{Desenvolvimento dos questionários}

O questionário foi dividido em duas grandes seções: a) a primeira, com 13 questões, buscava informações acerca do perfil dos respondentes; (b) a segunda, com 8 questões, tinha foco na experiência da empresa com a PE. Ao final do questionário ainda foi disponibilizado um campo para manifestações livres dos respondentes. Ao longo das 21 questões, cinco diferentes modalidades de respostas foram estabelecidas:

a) oito questões apresentavam campos para respostas textuais, tratando do nome do respondente, cargo, nome da empresa, cidade e Estado, principais produtos, número de funcionários, formação em nível de graduação e formação em nível de pós-graduação;

b) cinco questões permitiam respostas do tipo sim ou não (multinacional ou não; participação em 
treinamentos internos sobre PE; participação em eventos externos sobre PE; existência de programa formal para implantação da $\mathrm{PE}$; contratação de consultoria externa);

c) duas questões apresentavam possibilidades pré-definidas de resposta, sendo que apenas uma alternativa deveria ser assinalada (educação formal sobre PE; função na iniciativa de implantação da PE);

d) quatro questões apresentavam possibilidades pré-definidas de resposta, sendo que poderiam ser assinaladas todas as alternativas aplicáveis (razões para o interesse em adotar a PE; dificuldades na implantação da PE; práticas enxutas utilizadas pela empresa; práticas enxutas não aplicáveis à empresa). Com base em trabalhos de autores clássicos da área (LIKER, 2004; WOMACK; JONES, 1998; MONDEN, 1984; OHNO, 1997; SHINGO, 1996) nas duas questões acerca das práticas enxutas, foram estabelecidas 17 práticas que abrangiam, além das tradicionais aplicações no chão de fábrica (por exemplo, padronização do trabalho e troca rápida de ferramentas) a extensão da $\mathrm{PE}$ às áreas administrativas e cadeia de suprimentos (por exemplo, desenvolvimento de produto e logística). Uma vez que não há consenso na literatura acerca de quais são de fato todas as práticas enxutas (WHITE; PEARSON; WILSON,1999), nessas duas questões, assim como naquelas citadas no item (e) a seguir, havia um campo destinado à inclusão de outras respostas não pré-estabelecidas; $\mathrm{e}$

e) duas questões solicitavam o estabelecimento de uma pontuação de 1 até 5 . Na primeira questão, foi solicitada a indicação de cinco temas de PE em que o respondente tinha maior interesse em aprofundar conhecimentos, sendo que 5 representaria maior interesse e 1 representaria menor interesse. Nessa questão, foram acrescentados quatro temas às 17 práticas: cultura organizacional enxuta, estabilidade básica, sustentabilidade do sistema enxuto, tecnologia da informação (TI) e produção enxuta. Tais temas não foram entendidos como práticas, visto que se referem a dimensões da filosofia enxuta (cultura, estabilidade e sustentabilidade) ou que ainda não dispõem de ferramentas operacionais amplamente consolidadas de implantação, tais como tecnologia da informação (TI) e PE. Na segunda questão, foi solicitada a indicação das cinco práticas prioritárias para a empresa, sendo que 5 representaria maior prioridade e 1 menor prioridade. Nessa questão, foram apresentadas as mesmas 17 práticas das questões citadas no item $(d)$.

\subsection{Aplicação dos questionários e análise dos dados}

Após o seu desenvolvimento, o questionário foi disponibilizado na internet, em versões em português e inglês. Em relação ao questionário em português, a população alvo foi constituída por dois grupos: a) profissionais pós-graduados em engenharia de produção durante o período de 2001 até 2007 na instituição que conduziu a pesquisa $(\mathrm{n}=175)$, visto que tais informações estavam disponíveis no banco de dados da instituição; b) o cadastro de uma entidade que congrega empresas da cadeia automotiva na região onde foi realizada a pesquisa $(n=36)$. Tal entidade foi fundada por empresas da cadeia automotiva, entidades classistas e instituições de ensino para ser um agente de mudanças capaz de buscar a excelência do segmento, gerar projetos e ações, bem como dar uma abordagem inovadora ao desenvolvimento do setor.

O primeiro grupo foi escolhido, principalmente, pelo fato de muitos dos profissionais atuarem em empresas reconhecidas por adotarem a PE. Já o segundo grupo foi escolhido visto que o setor automotivo foi o berço do sistema de PE, sendo reconhecido como o mais avançado na sua disseminação.

É importante salientar que o questionário em português fez parte da já citada iniciativa de estabelecer um grupo de troca de experiências em PE. No momento em que receberam a solicitação de preenchimento do questionário, todos os membros da população alvo anteriormente citada foram convidados a participar desse grupo. De abril a dezembro de 2007, tal grupo realizou nove reuniões mensais, sendo cinco nas instalações das empresas envolvidas e quatro nas instalações da universidade. A rotina típica de cada reunião consistia das seguintes etapas: a) coffe-break para recepção e interação entre os participantes (30 minutos); b) apresentação da experiência da empresa em determinado assunto da PE, tais como kaizen, andons, mapeamento do fluxo de valor (MFV) ou lean construction (45 minutos); e c) visita ao chão de fábrica para visualização das práticas (45 minutos).

Tais reuniões contribuíram para a interpretação e análise das respostas do questionário, uma vez que os pesquisadores tiveram a oportunidade de conhecer melhor a implantação da PE em algumas das empresas dos respondentes. À medida que sejam estabelecidas relações de confiança e maior conhecimento entre os participantes, pretende-se que o grupo estabeleça um processo formal de benchmarking, definido como o processo sistemático de medir e comparar o desempenho de uma organização em relação ao 
desempenho de organizações similares em atividades críticas para o negócio (COSTA et al., 2006).

$\mathrm{O}$ questionário em inglês, por seu turno, teve como população alvo os membros de uma lista de discussão sobre PE (THE NORTHWEST LEAN NETWORKS, 2007). De acordo com informações apresentadas no site da lista, a mesma conta com cerca de 11.000 membros em todos os continentes, envolvendo profissionais de vários setores da indústria, acadêmicos e consultores interessados no tema PE. Entretanto, os responsáveis pelo gerenciamento dessa lista não permitem a submissão de mensagens que visem a realização de pesquisas junto aos seus membros, sendo essa possibilidade restrita a seus coordenadores. Devido a essa limitação, foi necessário enviar mensagens diretamente aos membros da lista a partir da identificação de seus endereços eletrônicos. Ao longo de um período de cinco meses, foram enviadas mensagens a 150 membros dessa lista. Para todas as respostas dos participantes estrangeiros, foram realizadas pesquisas em sites de busca para confirmar a existência da empresa e melhor compreender sua atividade.

Tanto as mensagens ao grupo brasileiro quanto ao grupo estrangeiro foram submetidas em lotes com não mais de 30 endereços eletrônicos, sendo que uma aplicação piloto do questionário em português ocorreu por meio da submissão individual a cinco participantes com os quais os autores já possuíam contatos pessoais. Devido à grande quantidade de informações geradas pelo questionário, a ênfase deste artigo é a apresentação de estatísticas descritivas e a realização da análise e interpretação dos dados qualitativamente com apoio da literatura.

\section{Resultados}

\subsection{Caracterização dos respondentes}

Considerando as três populações alvo que receberam convite para participar da pesquisa, as taxas de retorno de questionários válidos foram as seguintes: (a) profissionais com pós-graduação em engenharia de produção, atuando em empresas de diversos setores: 24 respondentes, ou 13,7\% para $\mathrm{n}=175$; (b) profissionais associados à entidade que congrega empresas da indústria automotiva, atuando em empresas desse setor: 6 respondentes, ou 16,7\% para $\mathrm{n}=36$; (c) profissionais da lista de discussão internacional, atuando em empresas de diversos setores: 15 respondentes, ou $10 \%$ para $n=150$. Além desses, três respondentes foram excluídos da tabulação uma vez que se referiam a empresas de consultoria e só haviam sido respondidas as questões acerca de suas informações pessoais e assuntos de maior interesse para aprofundar conhecimentos. Quatro respondentes não se enquadravam em nenhuma dessas três categorias e responderam ao questionário no âmbito de sua integração ao grupo de troca de experiências em PE. Todas as pessoas que foram se integrando a esse grupo ao longo de 2007, geralmente a partir de indicações de participantes, foram individualmente solicitadas a responderem ao questionário. Do total de 49 respondentes (em duas empresas houve mais de um respondente), 14 participaram ao menos de uma das nove reuniões do grupo de troca de experiências em PE ao longo de 2007. Em relação à nacionalidade, 34 dos respondentes são brasileiros e o restante é composto por estrangeiros.

A grande maioria $(77,6 \%, \mathrm{n}=38)$ cursou disciplinas sobre PE ao menos durante a graduação, sendo que $44,9 \%(\mathrm{n}=22)$ tiveram contato acadêmico com o tema apenas na pós-graduação. Nesse aspecto, houve grande diferença entre os brasileiros $(94,1 \%$ cursaram disciplina ao menos na graduação) e os estrangeiros (apenas $40 \%$ cursaram ao menos na graduação). Esse resultado é compreensível uma vez que parte dos profissionais brasileiros foi identificada pela lista de contatos da universidade.

Em relação ao recebimento de treinamentos internos na empresa acerca do tema nos últimos dois anos, 69,4\% ( $\mathrm{n}=34)$ dos respondentes relataram ter tido essa oportunidade, sendo que não houve grande diferença entre as respostas dos brasileiros $(67,6 \%$ tiveram treinamento) e as respostas dos estrangeiros (73,3\% tiveram treinamento). Foi citada uma ampla variedade de modalidades de treinamento, desde cursos com 80 horas de duração ministrados por empresas de consultoria especificamente para o pessoal da empresa, até a participação em eventos kaizen ou aplicações de mapeamento de fluxo de valor nas respectivas empresas. Cerca da metade dos respondentes $(51 \%$, $\mathrm{n}=25$ ) também participou de eventos externos (por exemplo, seminários, congressos e palestras) sobre PE nos útimos dois anos. Dentre os brasileiros, 47,1\% $(n=16)$ participaram de tais eventos, sendo que 60\% $(n=9)$ dos estrangeiros fizeram o mesmo.

Dentre os brasileiros, houve seis citações referentes a participações em eventos organizados por instituições como o Lean Institute Brasil (LIB) e o Instituto Gaúcho de Estudos Automotivos. O LIB é uma entidade de pesquisa, educação e treinamento dedicada à disseminação das ideias da PE (2007). Já dentre os estrangeiros, além de três citações referentes a eventos do Lean Enterprise Institute dos EUA, também houve duas citações referentes a eventos organizados pela Association for Manufacturing Excelence (AME), uma organização sem fins lucrativos que desempenha papel similar ao do Lean Institute, organizando eventos e cursos, bem como prestando assessoria a empresas no processo de implantação da PE.

Todos os respondentes eram profissionais de nível superior, sendo $83,7 \%(\mathrm{n}=41)$ engenheiros, $8,2 \%(\mathrm{n}=4)$ administradores, $4,1 \%(\mathrm{n}=2)$ químicos 
industriais, $2 \%$ advogados $(n=1)$ e $2 \%$ bacharéis em informática. Todos os respondentes que trabalhavam nas 30 empresas que possuíam programa formal de implantação da PE, com exceção de um indivíduo, exerciam atividades diretamente ligadas a ela, atuando na coordenação do projeto $(\mathrm{n}=14)$, como membro da equipe de coordenação $(n=13)$ ou como membro de grupo de melhoria contínua $(\mathrm{n}=3)$. Um respondente relatou atuar como membro da equipe de implantação em nível corporativo e como coordenador na filial em que trabalha, posição considerada para fins de tabulação dos resultados.

Considerando os dados acima apresentados, pode-se dizer que os respondentes do questionário são familiarizados com o tema PE, tanto em termos teóricos quanto práticos, motivo pelo qual se assume que as perguntas relativas às suas empresas foram respondidas de modo a retratar adequadamente a realidade delas. Trata-se de uma amostra estabelecida por conveniência, que atende às necessidades da pesquisa empreenida: familiaridade com os princípios e práticas enxutas.

\subsection{Caracterização das empresas}

Dentre as 47 empresas participantes da pesquisa, 15 são estrangeiras e 32 são brasileiras, sendo que, dentre as brasileiras, 30 estão sediadas no Rio Grande do Sul, uma em São Paulo e uma em Minas Gerais. Dentre as 15 empresas estrangeiras, uma está sediada no México e as restantes estão distribuídas entre diversos Estados dos EUA. De acordo com a Figura 1, a maior parte $(n=21,44,7 \%)$ das 47 empresas é do setor automotivo, o que inclui duas montadoras de automóveis, uma montadora de tratores, uma montadora de ônibus e uma empresa estrangeira cuja atividade é a customização de trailers. As dezesseis empresas restantes do setor automotivo são fornecedoras de componentes para as montadoras. $\mathrm{O}$ segundo setor mais representativo foi o de equipamentos eletroeletrônicos, tais como condicionadores de ar e medidores elétricos. Empresas de onze outros setores também participaram com menor representatividade, havendo até mesmo um hospital nos EUA. Nesse caso, o respondente relatou atuar especificamente com a função de implantar a PE, autointitulando seu cargo com o termo lean business process manager. De fato, há diversos relatos na literatura (RAAB et al., 2006) indicando experiências bem-sucedidas de implantação da PE no setor da saúde, principalmente nos EUA e Reino Unido.

Em relação ao número de funcionários, $51,1 \%$ $(n=24)$ das empresas podem ser classificadas como de grande porte (500 ou mais funcionários), 29,8\% $(\mathrm{n}=14)$ como de médio porte (101 a 499 funcionários) e $19,1 \%(n=9)$ como pequenas ou microempresas (1 a 100 funcionários). Dentre as empresas brasileiras, a de maior porte é uma montadora de automóveis com cerca de 2800 funcionários. Dentre as empresas estrangeiras, a de maior porte é uma fabricante de equipamentos médicos situada nos EUA, com 9000 funcionários.

A maior parte das empresas $(63,4 \%, \mathrm{n}=30)$ possui um plano formal para implantação da produção enxuta, com definição de responsáveis, metas, cronograma e priorização de ações. Contudo, a formalização é mais comum entre as empresas estrangeiras $(80 \%$, $\mathrm{n}=12)$ do que entre as empresas brasileiras $(56,3 \%$, $\mathrm{n}=18$ ). As empresas estrangeiras também têm recorrido mais ao uso de consultorias para apoiar a iniciativa enxuta (60\% das estrangeiras e $28,1 \%$ das brasileiras). Considerando todas as empresas envolvidas na pesquisa, menos da metade $(38,3 \%$, $\mathrm{n}=18$ ) contratou consultorias.

A maior parte das empresas é multinacional $(59,6 \%$, $\mathrm{n}=28$ ), sendo uma delas uma multinacional brasileira do setor de siderurgia. O tempo de implantação da PE nas empresas participantes é apresentado na Tabela 1 , a partir da qual se pode concluir que o tempo médio de implantação é de 4,9 anos, contados retrospectivamente

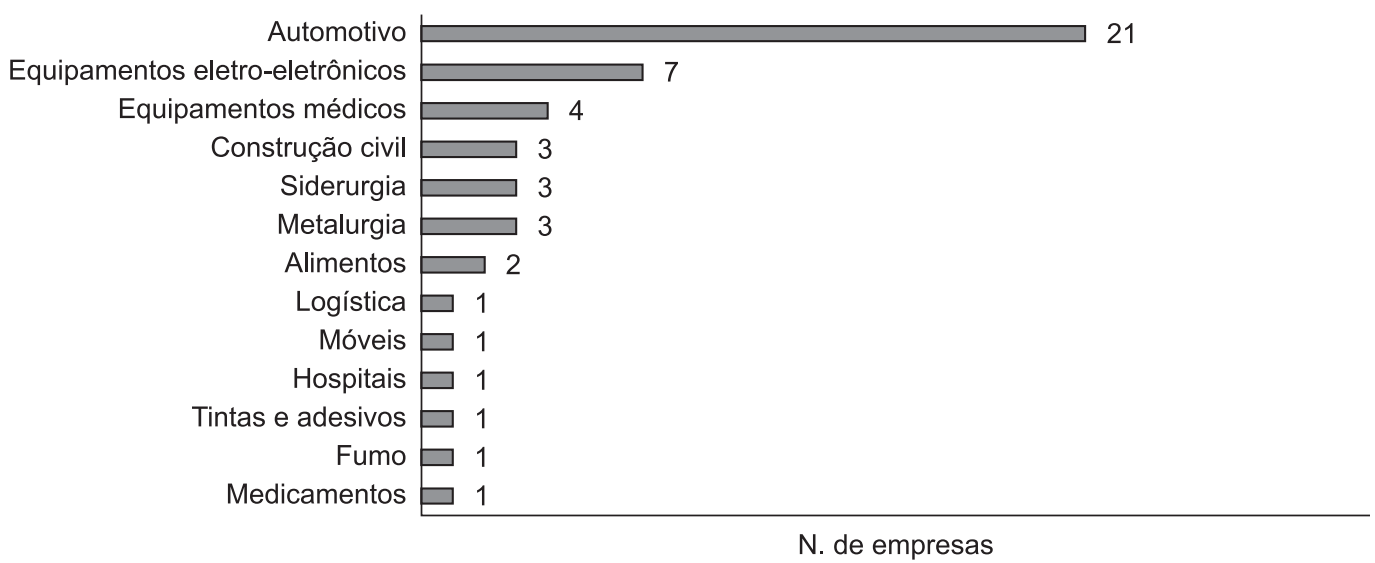

Figura 1. Principais produtos das empresas participantes da pesquisa. 
a partir de 2008. Em cerca da metade das empresas $(48,9 \%, \mathrm{n}=23)$, a implantação foi iniciada a partir de 2002 , sendo que apenas 4 empresas $(8,5 \%)$ relataram ter iniciado a implantação há mais de 10 anos. Vale salientar que em duas empresas houve projetos alinhados com a PE ainda na década de 80 , tais como Troca Rápida de Ferramentas (TRF) e Manutenção Produtiva Total (MPT). Contudo, apenas nos últimos cinco anos essas empresas integraram tais projetos isolados ao contexto da implantação de um sistema produtivo enxuto em toda a organização.

Considerando-se os dados apresentados neste item, de modo geral, pode-se caracterizar as empresas participantes como sendo da indústria da transformação, de médio ou grande porte, multinacionais e com histórico recente de implantação da PE como filosofia de manufatura.

\subsection{Assuntos de maior interesse em ampliar conhecimentos}

A Figura 2 apresenta os assuntos em que os respondentes têm maior interesse em aprofundar seus conhecimentos. Pode-se perceber que a cultura organizacional enxuta e o mapeamento do fluxo de valor aparecem como temas de maior destaque. Em relação à cultura, o interesse pode ser parcialmente explicado por dois motivos: a) apenas recentemente esse tema tem ganhado destaque na literatura, com publicações bastante focadas nele; e b) diversos estudos (LIKER, 2004; SPEAR; BOWEN, 1999) apontam que a implementação bem sucedida da PE depende fortemente da compreensão dos princípios e valores essenciais do sistema de PE, mais do que simplesmente a adoção das práticas. De fato, no campo do questionário destinado a manifestações livres dos respondentes, três pessoas usaram-no para enfatizar

Tabela 1. Tempo de implantação da Produção Enxuta nas empresas participantes da pesquisa.

\begin{tabular}{cc}
\hline Ano de início & $\mathbf{N}^{\mathbf{0}}$ de empresas \\
\hline 2007 & 5 \\
2006 & 5 \\
2005 & 5 \\
2004 & 4 \\
2003 & 2 \\
2002 & 2 \\
2000 & 1 \\
1999 & 1 \\
1998 & 1 \\
1997 & 2 \\
1994 & 1 \\
1992 & 1 \\
\hline
\end{tabular}

que, de acordo com as suas experiências, a cultura enxuta é o fator mais importante a ser considerado, sendo que as práticas são de importância secundária. Um desses três respondentes ainda salientou que uma característica de empresas com cultura enxuta consolidada é a sustentabilidade dos avanços obtidos e a melhoria contínua, percepção com amplo respaldo na literatura e bastante típica da realidade da Toyota (LIKER, 2004). Nesse sentido, também cabe observar que a sustentabilidade foi o quinto tema de maior interesse. Esses resultados podem indicar que muitas das empresas já superaram a fase de implantação das práticas enxutas básicas (o tempo médio de adoção é 4,9 anos) e se encontram agora em um estágio cuja principal preocupação é manter e expandir os ganhos, o que depende fortemente da disseminação de uma nova cultura organizacional.

Em relação ao mapeamento do fluxo de valor, o interesse pode ser devido ao fato de que essa ferramenta proporciona um diagnóstico inicial do sistema de manufatura e apresenta diretrizes para implantação de princípios básicos, tais como gerenciamento com base no takt time, estabelecimento de limites para estoque em processo e programação da produção em um único processo (ROTHER; SHOOK, 1998).

De outro lado, o tema de menor interesse diz respeito à integração da PE com a gestão da segurança, saúde no trabalho e meio ambiente (produção enxuta e SSMA). Embora esse baixo interesse reflita a falta de ênfase da PE na melhoria das condições de trabalho, o resultado também indica que os respondentes não estão conscientes do potencial de benefícios que podem ser obtidos a partir da integração dos fatores humanos no âmbito da PE. Por exemplo, há oportunidade para introduzir no sistema de PE o balanceamento da carga de trabalho entre os operadores, o que não significa necessariamente o balanceamento de tempos de ciclo. De acordo com NASA TLX (NASA..., 1986), a carga de trabalho é um construto multidimensional, o qual é influenciado por fatores como demanda mental, demanda física, nível de frustração e capacitação dos operadores. Similarmente, a agência ambiental dos EUA (UNITED..., 2006) reconhece que a ênfase da PE na redução de desperdícios é bastante favorável para a redução do impacto ambiental dos sistemas produtivos, havendo amplas oportunidades para a integração dos esforços enxutos e de gestão ambiental. Vale ainda salientar que impactos indesejados da PE nas condições de trabalho (por exemplo, aumento de estresse e intensidade de trabalho) têm sido discutidos em diversos estudos, inclusive no Brasil (SAURIN; FERREIRA, 2009), como uma das principais críticas a esse sistema, o que também justifica a necessidade de melhor consideração dos fatores humanos.

Dentre os resultados da Figura 2, também chama a atenção o interesse muito baixo pelo tema autonomação, o qual é considerado por Shingo (1996) 
como um dos pilares do Sistema Toyota de Produção. De acordo com aquele autor, a autonomação é caracterizada pela separação entre homem e máquina, sendo que essa última deve ser capaz de operar independentemente de monitoramento do operador, bem como possuir dispositivos de parada automática em caso de detecção de anormalidades.

Conforme a experiência dos autores, por meio de conversas informais com vários respondentes durante as visitas do grupo de troca de boas práticas, o resultado da pesquisa pode ser decorrente da falta de entendimento do conceito de autonomação, o qual é frequentemente confundido com o termo automação. Além disso, o conceito de poka-yokes, os quais são mecanismos que podem viabilizar a autonomação de um equipamento, por vezes não era devidamente compreendido. Em uma das visitas, foi verificado que a empresa denominava de poka-yoke um gabarito que servia para inspeção dimensional de peças recém-usinadas. $\mathrm{O}$ gabarito era fisicamente independente da máquina, localizado ao lado dela. Entretanto, uma vez que a inspeção não era feita em $100 \%$ das peças, bem como dependia de ação do operador para ser realizada, não poderia caracterizar o uso de poka-yoke, conforme Shingo (1996).

\subsection{Motivações para adotar a Produção Enxuta}

A Figura 3 apresenta as principais razões apontadas para o interesse em adotar a PE. As características de visão de longo prazo e melhoria contínua de uma cultura enxuta (LIKER, 2004) requerem convicção acerca das motivações em adotar essa filosofia, o que vai garantir sua manutenção mesmo em detrimento de eventuais perdas no curto prazo. Duas razões apresentaram claro destaque: a) necessidade de melhorar a competitividade; e b) adequação da PE ao combate de problemas críticos da produção. De fato, há amplas evidências na literatura de que o forte foco da PE no combate às perdas pode trazer ganhos substanciais em critérios competitivos tradicionais, tais como qualidade, prazos de entrega e custos. Além disso, a disseminação da PE em vários setores da indústria e serviços indica que é suficientemente generalizável para ser aplicada em ambientes aparentemente bastante distintos. As outras razões apresentadas pelos respondentes, além daquelas apresentadas no questionário, foram as seguintes: exigências dos clientes (duas citações, fabricante de equipamentos elétricos e fabricante de componentes para a indústria automotiva); redução de desperdícios (uma citação, fabricante de utensílios para a indústria gastronômica); aumento da capacidade sem aumentar a força de trabalho (uma citação, hospital); aumentar a margem de lucro (uma citação, componentes para indústria automotiva); reduzir lead time para aumentar vendas (uma citação, equipamentos elétricos); sair da zona de conforto antecipando futuras dificuldades (uma citação, metalúrgica fabricante de telas metálicas); e a característica de melhoria contínua da PE (uma citação, fábrica de alimentos). De modo geral, esses

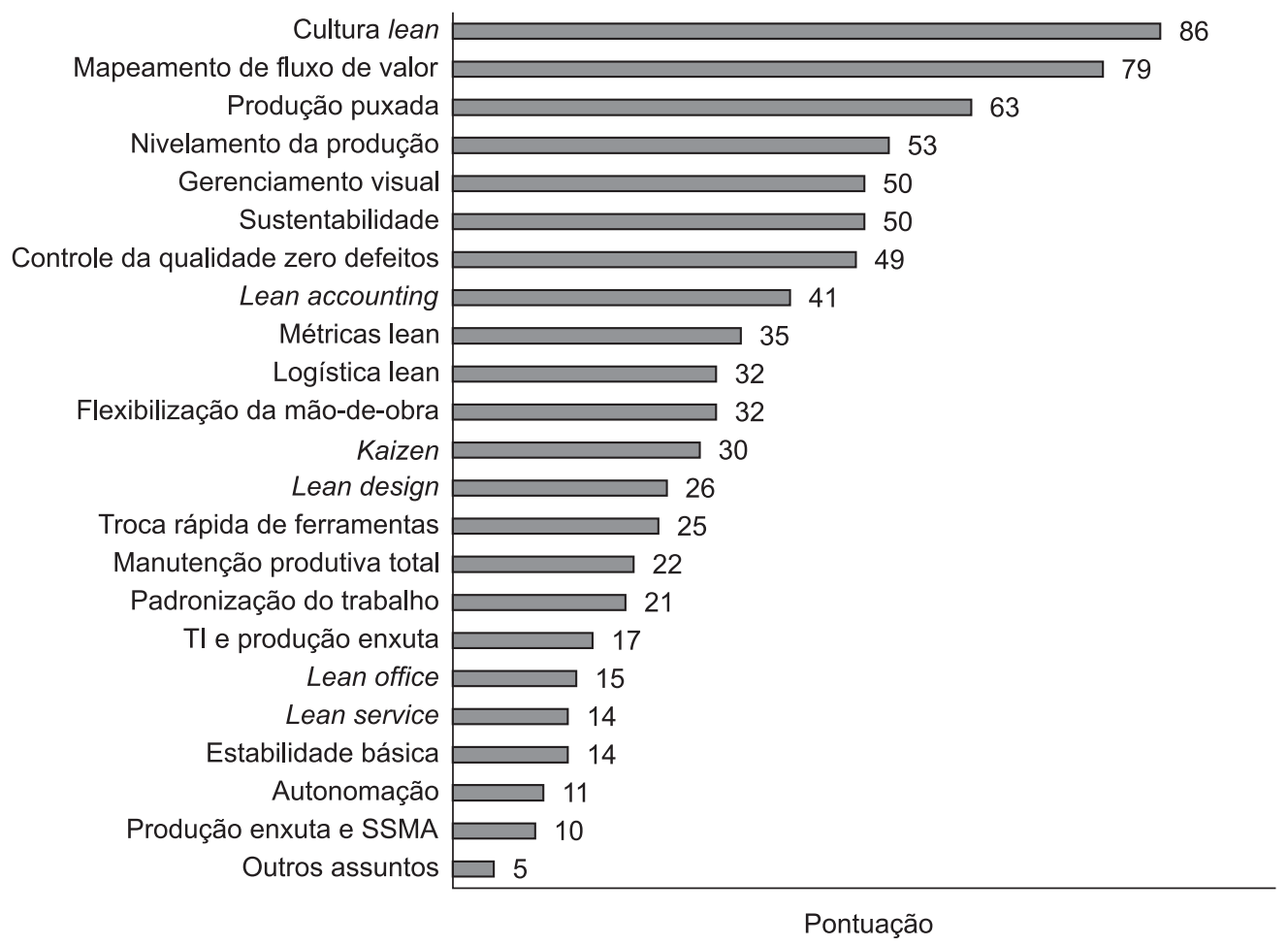

Figura 2. Assuntos de maior interesse em aprofundar conhecimentos. 
resultados indicam que a iniciativa de implantar a $\mathrm{PE}$ poucas vezes tem partido de imposições de clientes e de políticas corporativas. De um lado, essa característica é positiva, pois indica real interesse na implantação. De outro lado, a falta de obrigação formal de adotar a PE pode ser um fator adicional de desestímulo se os ganhos esperados demorarem a ocorrer.

\subsection{Principais dificuldades de implantação}

A questão relativa às principais dificuldades enfrentadas durante a implantação da PE (Figura 4) também apresentou clara preponderância de duas das opções disponibilizadas no questionário: resistência das pessoas às mudanças e dificuldade em adaptar conceitos e práticas. Esses dois fatores também se salientaram como as duas maiores dificuldades de implantação na pesquisa realizada pelo LEI (LEAN ENTERPRISE..., 2007), sendo que, dentre a resistência das pessoas, foram preponderantes as menções à resistência da média gerência. Já a survey conduzida por Golhar, Stamm e Smith (1990), junto a 20 pequenas empresas dos EUA que adotavam a PE, identificou que, além da resistência de operários e sindicatos, outras dificuldades eram a falta de qualidade das peças adquiridas de fornecedores externos e os altos custos com mudanças de layout.

No âmbito da presente pesquisa, as menções à resistência das pessoas são coerentes com o interesse dos respondentes em conhecer mais sobre cultura organizacional enxuta. De fato, em uma cultura enxuta é necessária uma mudança de mentalidade e atitudes em todos os níveis hierárquicos, o que naturalmente tende a gerar resistências. Por exemplo, uma cultura enxuta valoriza princípios que não são comuns em ambientes de produção Tayloristas-Fordistas, tais como produzir apenas o necessário, aperfeiçoar continuamente o trabalho padronizado e coletar e analisar indicadores de processo, ao invés de apenas os indicadores de resultado (MANN, 2005; LIKER, 2004).

De outro lado, embora os respondentes tenham a percepção de que a PE é adequada ao combate de problemas críticos da produção, parece haver dificuldade em saber exatamente como isso pode ser operacionalizado, visto que foi apontada a dificuldade de adaptar conceitos e práticas.

A falta de recursos financeiros não apareceu como dificuldade significativa, o que pode ser explicado tanto pelo médio e grande porte da maior parte das empresas, quanto pela característica da PE de não priorizar investimentos em novas tecnologias e equipamentos, mas sim em novas formas de organização do trabalho. Por exemplo, em uma das empresas visitadas no âmbito do grupo de troca de experiências, foi observado que não existia no orçamento anual uma conta especificamente dedicada à iniciativa enxuta. De acordo com um representante da empresa, os gastos mais substanciais e visíveis têm ocorrido com treinamentos de gerentes que serão disseminadores da PE na empresa.

\subsection{Práticas enxutas mais utilizadas}

Em relação às práticas que as empresas participantes utilizam ou já utilizaram, não houve forte preponderância de nenhuma das opções, sendo que as sete primeiras indicadas na Figura 5 podem ser

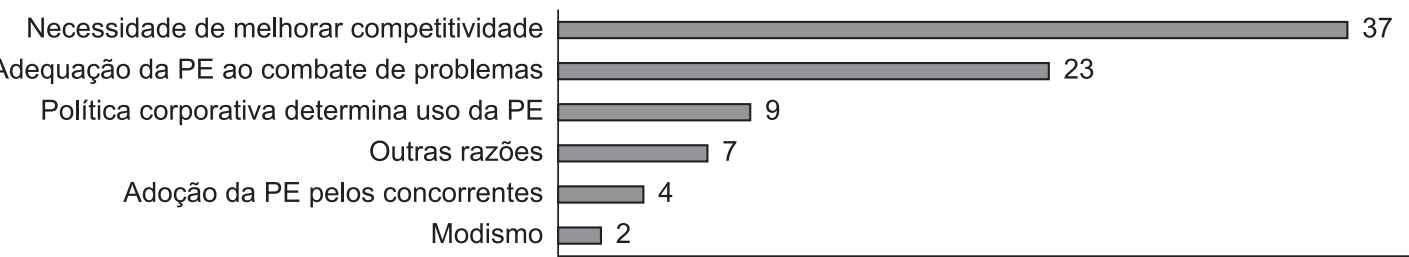

N. de respostas

Figura 3. Principais razões para adotar a Produção Enxuta.

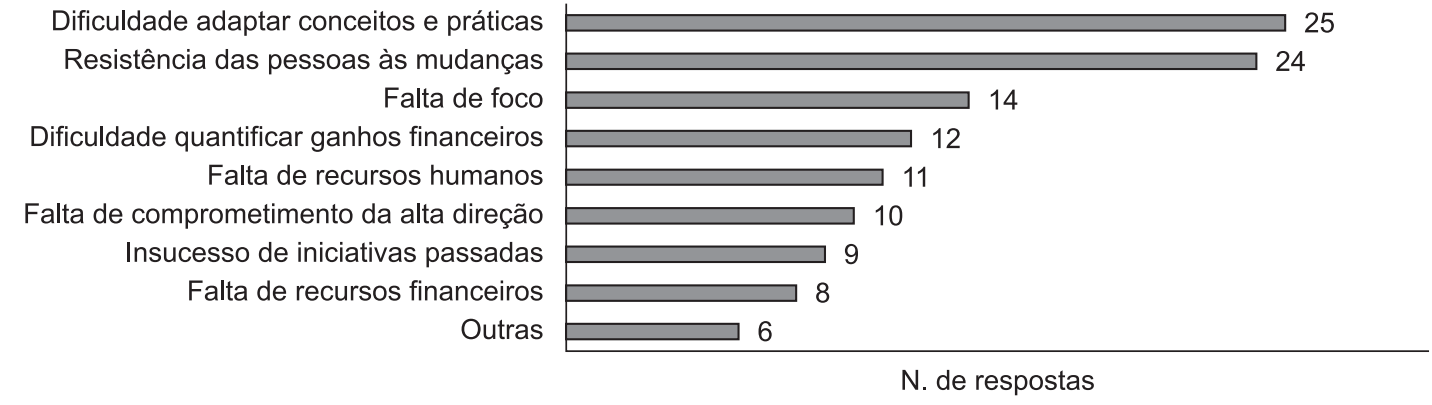

Figura 4. Principais dificuldades para implantar a Produção Enxuta. 
destacadas. Esse resultado é consistente com a já mencionada percepção de que a maioria das empresas já tem boa experiência acumulada com as práticas mais tradicionais, estando possivelmente em um estágio de amadurecimento e ampliação.

A alta utilização da padronização do trabalho (31 citações) reflete o fato de que essa prática é requisito básico para garantir estabilidade no sistema produtivo, além de estar associada também a sistemas de produção em massa, visto que a ideia de padronização foi originalmente proposta e disseminada por Taylor há cerca de cem anos. Além disso, a padronização foi amplamente disseminada na indústria brasileira nas décadas de 80 e 90 no âmbito dos programas de qualidade total. Entretanto, é necessária uma investigação aprofundada para verificar se a padronização vem sendo implementada segundo a filosofia enxuta ou segundo a abordagem de padronização Taylorista-Fordista. Padrões de trabalho na ótica enxuta devem ser desenvolvidos conjuntamente com os operadores que os cumprirão, bem como devem ser constantemente auditados (preferencialmente em tempo real, com apoio de técnicas de gerenciamento visual) e entendidos como melhores práticas momentâneas, sujeitas a modificações tão logo práticas mais eficazes sejam identificadas (LIKER, 2004; SPEAR; BOWEN, 1999). $\mathrm{Na}$ ótica enxuta, os supervisores e gerentes também devem ter seu trabalho padronizado, embora com maiores graus de liberdade em função da natureza de suas atividades (MANN, 2005). A experiência dos autores durante as visitas às empresas do grupo de troca de experiências indica que a padronização nesses moldes ainda parece incipiente nas empresas da região, sendo muitas vezes restrita a poucas áreas piloto dentro das plantas.

O forte uso do gerenciamento visual (30 citações) pode ser explicado pela relativa facilidade de implantação dessa prática e pela facilidade de perceber sua implantação. Assim como ocorre com a padronização, o gerenciamento visual também tende a ser bastante aplicado por ser uma prática conhecida e disseminada relativamente há bastante tempo nas empresas brasileiras por meio dos programas $5 \mathrm{~S}$. Outros fatores que favorecem a disseminação dessa prática são as exigências legais quanto à implantação de sinalização de segurança e saúde no trabalho, bem como a prática de muitas empresas de disponibilizar resultados de indicadores de desempenho em murais junto às áreas de trabalho.

A justificativa para o pouco uso de algumas práticas possivelmente está associada ao pouco conhecimento dos respondentes em relação a elas. Por exemplo, a prática lean accounting apareceu como a $17^{\mathrm{a}}$ mais utilizada, embora tenha sido citada como a $8^{\mathrm{a}}$ prática de maior interesse em aprofundar conhecimentos. Similarmente, o nivelamento da produção apareceu como a $11^{\text {a }}$ prática mais utilizada, sendo a $4^{\text {a }}$ de maior interesse. De outro lado, algumas práticas revelaram tanto baixo interesse em aprofundar conhecimentos como pouco uso. Dentre essas, cabe destacar a autonomação que, embora seja conhecida como um dos pilares do STP, apareceu como a $16^{\mathrm{a}}$ mais utilizada e a $21^{\text {a }}$ de maior interesse. Outras práticas possivelmente apresentaram baixo uso devido às características das empresas respondentes. Por exemplo, o baixo uso do desenvolvimento de produto enxuto (6 citações, $19^{\mathrm{a}}$ posição) possivelmente é consequência de que, em muitas das empresas participantes, essa atividade fica a cargo das matrizes das empresas, as quais são situadas em outros países.

\subsection{Práticas enxutas prioritárias}

A Figura 6 apresenta as práticas prioritárias para as empresas no período da pesquisa, confirmando a baixa importância atribuída pelas empresas à autonomação e à integração da PE com a segurança, saúde e meio ambiente.

De outro lado, pode-se observar o destaque das práticas de produção puxada e padronização do trabalho ( $1^{\mathrm{a}}$ e $2^{\mathrm{a}}$ posição, respectivamente). A alta prioridade atribuída a essas práticas é positiva, uma vez que puxar a produção é um dos princípios fundamentais da PE (WOMACK; JONES, 1998), enquanto que a padronização é base para a melhoria contínua, outro princípio fundamental, conforme Womack e Jones (1998).

A produção puxada também apresentou alto interesse dos respondentes em aprofundar conhecimentos ( $3^{\mathrm{a}}$ posição) e foi a $5^{\mathrm{a}}$ prática mais utilizada. Já a padronização apresentou interesse bastante menor na ampliação de conhecimentos (16 $6^{\mathrm{a}}$ posição), embora tenha sido a $1^{\text {a }}$ mais utilizada. Desse modo, embora tanto a produção puxada quanto a padronização tenham alta prioridade e venham sendo bastante utilizadas, os participantes parecem se sentir menos aptos para a implantação da primeira em função do conhecimento insuficiente acerca do tema. Assim, uma vez que a produção puxada foi citada como uma prática de uso bastante frequente, é provável que muitas empresas tenham apenas alguns fluxos funcionando de modo puxado ou mesmo não possuam sistemas puxados, apesar da resposta positiva no questionário.

Tal percepção foi confirmada durante uma visita a um fornecedor de componentes para a indústria automotiva (empresa de pequeno porte), no âmbito do grupo de troca de experiências. Embora a área de manufatura dessa empresa consistisse de apenas três células de produção interligadas, cada uma recebia ordens de produção individuais do setor de $\mathrm{PCP}$ e não havia limite para o estoque em processo entre as células, logo não caracterizando um sistema puxado (SMALEY, 2004). Apesar disso, o 


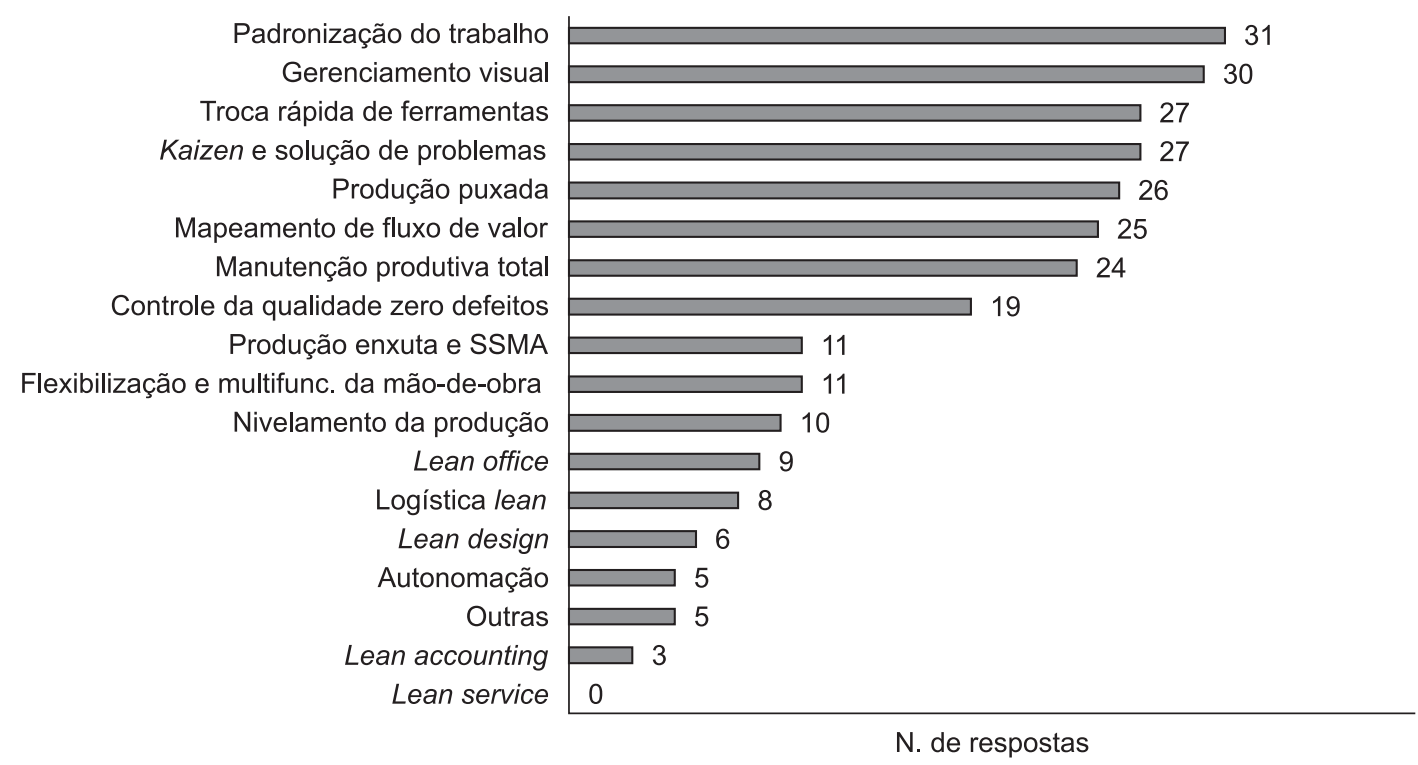

Figura 5. Práticas que as empresas respondentes utilizam ou já utilizaram.

respondente correspondente a essa empresa assinalou no questionário que a produção puxada era uma das práticas utilizadas.

De fato, em que pese a relativa popularização do conceito de cartões kanban, a ferramenta operacional mais conhecida para implantar a produção puxada, a literatura acerca do tema deixa claro que há certa complexidade envolvendo a implantação dessa prática, havendo diversas modalidades de implantação, bem como diversos pré-requisitos para viabilizar seu sucesso, tais como a disciplina para o cumprimento das regras de um sistema puxado e o dimensionamento de estoques intermediários (SMALEY, 2004).

De outro lado, uma visita a uma segunda fornecedora de componentes para montadoras de automóveis (dessa vez uma empresa de grande porte) confirmou a resposta da pesquisa com relação à produção puxada. $\mathrm{O}$ respondente havia assinalado que não havia uso da produção puxada e que essa era a prática de maior prioridade no momento. De fato, nessa empresa havia um quadro que exibia resultados de indicadores destinados a avaliar seu progresso em direção à PE. Tal quadro era denominado lean scorecard e incluía um indicador que avaliava o percentual de células que funcionavam de modo puxado. Conforme os resultados expostos no dia da visita, o resultado de tal indicador se encontrava na menor faixa de desempenho ( $<25 \%$ dos processos puxados). Vale salientar que, nesse caso, os membros da empresa reconheciam que a produção era empurrada, ainda que, segundo eles, todas as ordens de produção incluíssem apenas pedidos firmes de clientes.

Já a prioridade atribuída à padronização reforça a percepção dos pesquisadores de que, embora as empresas estejam familiarizadas com as ideias básicas dessa prática, sua implantação ainda está restrita a áreas piloto. Isso é compreensível uma vez que a padronização requer trabalho intensivo de coleta de tempos de ciclo, identificação de desperdícios e projeto do trabalho de cada operador, bem como a constante revisão e melhoria contínua desses parâmetros. Assim, especialmente em empresas de médio e grande porte, as quais são maioria no grupo estudado, é maior a quantidade de operadores a terem o trabalho padronizado, o que requer constância de propósitos da alta gerência para a ampla consolidação da prática.

A padronização do trabalho também é um requisito para que a empresa atinja a estabilidade básica necessária ao aprofundamento da PE. Em particular, a padronização contribui para a estabilidade da mão de obra e dos resultados de seu trabalho, uma vez que define os métodos aceitos como corretos e como consequência facilita a identificação de eventuais variações.

Vale salientar que o grau intermediário de prioridade atribuído à TRF ( $7^{a}$ posição) e à TPM ( $8^{a}$ posição) possivelmente pode ser associado ao fato de estarem razoavelmente consolidadas em boa parte das empresas participantes (TRF foi a $4^{\mathrm{a}}$ prática mais utilizada e TPM a $7^{\mathrm{a}}$, conforme a Figura 5).

\subsection{Práticas não aplicáveis às empresas}

A Figura 7 apresenta as práticas não aplicáveis às empresas participantes da pesquisa. A resposta mais frequente $(44,9 \%$ dos respondentes) foi a de que todas as práticas são aplicáveis, o que é coerente com a atual disseminação da $\mathrm{PE}$ em vários setores, bem como com o fato de a maioria das empresas 
pertencer ao setor automotivo, no qual as práticas da PE são mais facilmente adaptáveis.

Entretanto, a grande quantidade de respostas afirmando que havia ao menos uma prática não aplicável é coerente com os resultados da Figura 4, que indicavam dificuldade de adaptação de conceitos e práticas. Além disso, tais resultados reforçam a percepção de conhecimento insuficiente acerca da real natureza das práticas por parte de muitos respondentes. De fato, é necessário um alto grau de abstração dos princípios essenciais que embasam as práticas enxutas para visualizar sua aplicação em diferentes cenários (LILLRANK, 1995).
Por exemplo, respondentes das empresas de construção civil assinalaram que a padronização do trabalho e a troca rápida de ferramentas não são aplicáveis ao seu contexto. Contudo, a análise dos princípios essenciais da TRF, tais como a separação entre setup interno e externo (SHINGO, 1996), indica que pode ser, e possivelmente muitas vezes já seja aplicada, em canteiros de obra. Como exemplo, a preparação com antecedência das vias de circulação de carrinhos de mão sobre uma laje a ser concretada pode ser interpretada como a realização de uma atividade de setup externo, visto que isso vai minimizar o tempo de parada dos caminhões betoneira que abastecem o

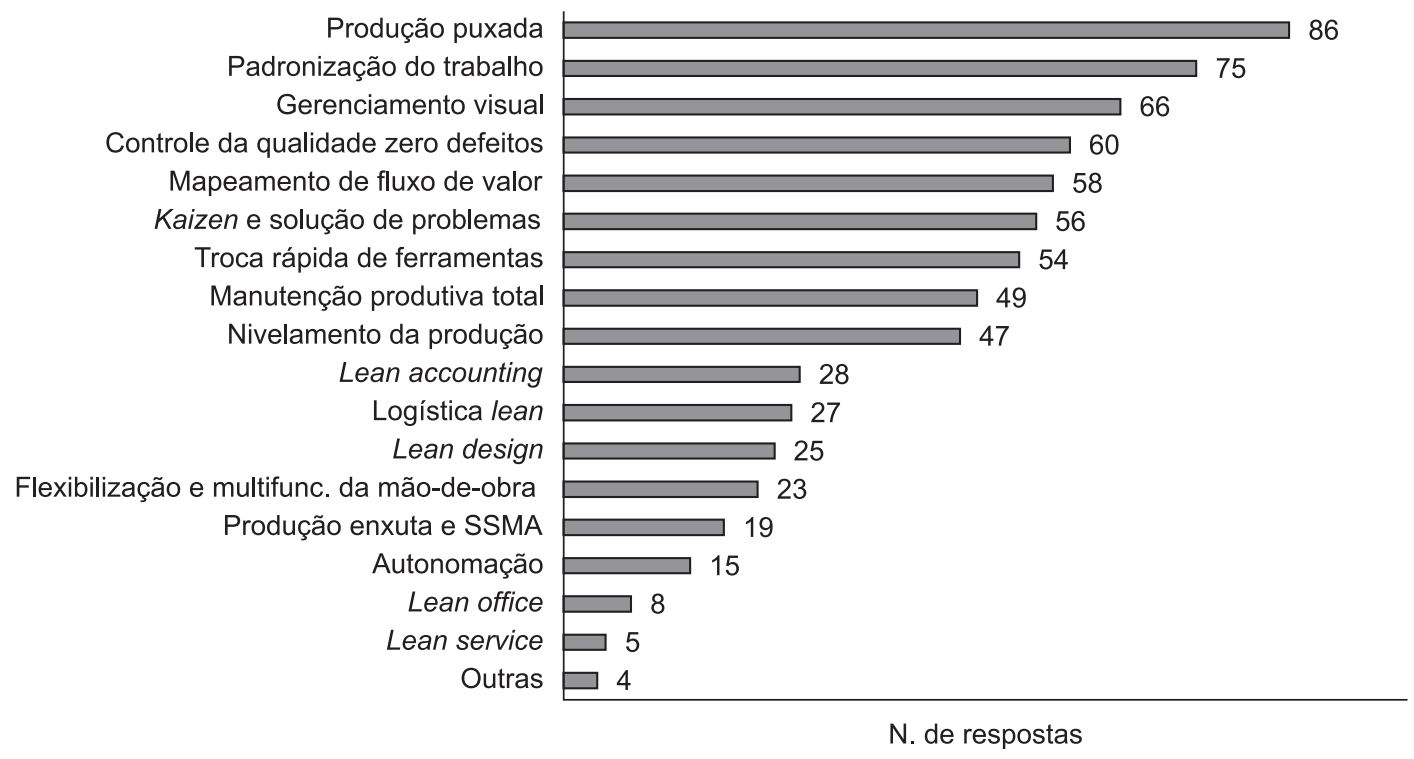

Figura 6. Práticas prioritárias.

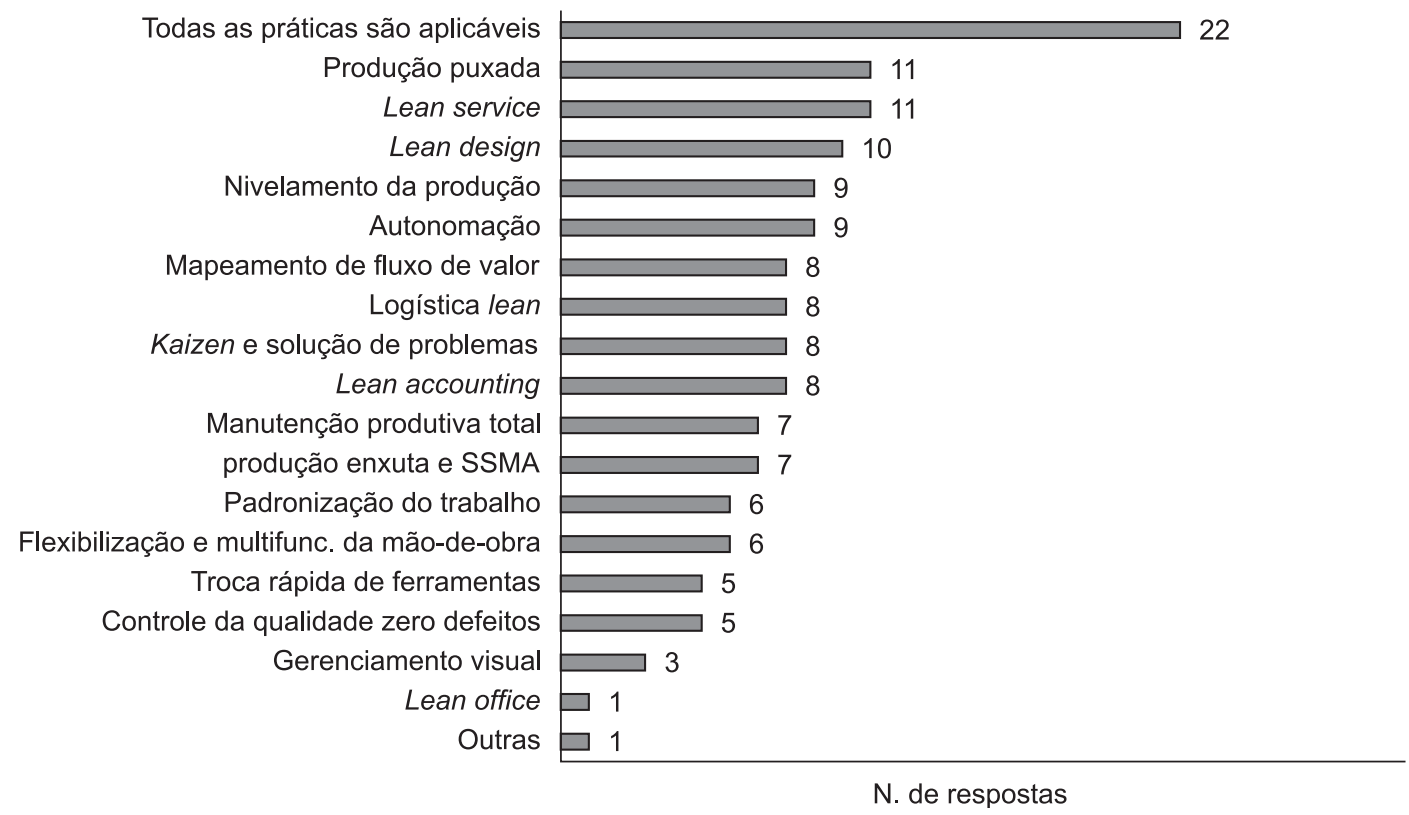

Figura 7. Práticas não aplicáveis ao contexto da empresa. 
concreto pré-misturado no canteiro. De outro lado, a padronização do trabalho no nível de detalhar tempos e movimentos de operadores, conforme prática usual na indústria da manufatura, tende a ser de pouca valia e aplicabilidade em canteiros de obra. Contudo, a adaptação da prática para os canteiros de obra significa reconhecer os maiores graus de liberdade necessários aos operadores, mas ainda assim incluir a determinação de sequências de montagem, locais de estocagem de materiais e procedimentos de qualidade e segurança no trabalho.

\section{Conclusões}

Este artigo apresentou os resultados de uma pesquisa exploratória acerca da implantação da PE. A pesquisa reuniu respostas de 49 indivíduos que representavam 47 empresas sediadas no Brasil e no exterior. Tais empresas têm como principal característica em comum as posições de destaque nos respectivos setores e a adoção da PE, em diferentes níveis. Os resultados deste estudo contribuíram para a identificação de necessidades e oportunidades de pesquisas acerca da implantação da PE, as quais são sumarizadas e discutidas a seguir.

Destaca-se a necessidade de investigar a relação entre a eficácia e a eficiência da implantação e o conhecimento que os gerentes e operadores possuem acerca das práticas e da filosofia enxuta. No presente estudo, embora a maior parte dos respondentes tenha recebido educação formal sobre PE na universidade ou na empresa, houve indícios de que a investigação proposta é necessária, pois se observou: a) desconhecimento, interpretação equivocada ou simplesmente diferentes interpretações acerca de conceitos-chave para a PE, tais como autonomação, produção puxada e poka-yokes; b) grande número de respostas indicando que havia práticas não aplicáveis ao contexto da empresa (55,1\% dos respondentes), revelando dificuldades de abstração dos princípios da PE; c) frequente uso de consultorias durante a implantação da PE (38,3\% das empresas), o que pode implicar em dificuldades de aprendizado pelos membros da empresa se a responsabilidade pela implantação for excessivamente delegada aos consultores; e d) a citação da dificuldade em adaptar conceitos e práticas como a barreira mais frequente para implantar a PE. A pertinência deste tópico de pesquisa também pode ser justificada pela ampla disseminação de manuais e guias práticos como referências importantes para a implantação da $\mathrm{PE}$, o que, embora seja positivo em função da ênfase em disseminar a aplicação da filosofia, pouco estimula o senso crítico e o aprofundamento de conceitos.

O conhecimento mais aprofundado acerca das principais dificuldades de implantação também é essencial para que as pesquisas estejam alinhadas com as necessidades reais das empresas. Por exemplo, quais conceitos e práticas são mais difíceis de adaptar em quais contextos? Como as pessoas estão resistindo à implantação da PE? Qual o contexto organizacional em que estão inseridas as pessoas que resistem? Como as empresas vêm lidando com isso?

Ainda no contexto das dificuldades de implantação, é de particular importância investigar como os fatores humanos vêm sendo considerados. O levantamento apresentado neste artigo revelou que esse tema requer novos estudos, pois foi observado: a) baixa atenção dispensada ao tema integração da PE com segurança, saúde e meio ambiente; b) grande interesse dos respondentes em ampliar conhecimentos acerca do tema cultura organizacional enxuta, uma vez que a sustentabilidade da PE requer mudanças nos valores e atitudes dos membros da organização; e c) resistência das pessoas às mudanças como uma das principais barreiras para a implantação da PE. Em particular, uma oportunidade é a investigação de quais práticas com ênfase no subsistema social das organizações (por exemplo, práticas de recursos humanos, treinamento e segurança e saúde no trabalho) vêm sendo usadas em conjunto com as práticas enxutas, que por natureza enfatizam o subsistema técnico. Com base nisso, podem ser identificadas combinações de práticas que contribuam para o equilíbrio do sistema de manufatura sob uma perspectiva sócio-técnica.

Outra necessidade diz respeito à investigação da relação entre o tempo de adoção formal da filosofia de PE e as práticas já utilizadas e práticas prioritárias, o que pode indicar a existência de sequências ótimas de implantação e quais práticas devem ser inicialmente adotadas para estabilizar o sistema de manufatura. Nesse contexto, também será necessário definir como a estabilidade pode ser avaliada.

A investigação acerca da relação entre as motivações para adotar a PE e o sucesso da implantação também merece estudos. Embora alguns fatores motivadores possam ser em princípio associados a bons (por exemplo, superar crises) ou maus resultados (por exemplo, imposição da matriz), não há evidências estatísticas que comprovem tais relações.

O questionário utilizado neste estudo também pode constituir uma base para um novo instrumento especificamente concebido para a realização de pesquisas periódicas de acompanhamento da evolução da indústria nacional na implantação dos conceitos de PE. Tal instrumento poderia ser explicitamente desenvolvido para que fosse possível a avaliação de correlações estatísticas acerca das relações anteriormente citadas. Tal proposta teria maior probabilidade de sucesso se a pesquisa for conduzida como uma iniciativa conjunta de universidades e instituições ligadas à indústria e à disseminação do conhecimento em PE. 


\section{Referências}

BAKER, P. Why is lean so far off? Works Management, p. 1-4, 2002.

COSTA, D. et al. Benchmarking initiatives in the construction industry: lessons learned and improvement opportunities. Journal of Management in Engineering, p. 158-167, 2006.

CUA, K.; McKONE, K.; SCHROEDER, R. Relationships between implementation of TQM, JIT, and TPM and manufacturing performance. Journal of Operations Management, v. 19, p. 675-694, 2001.

GOLHAR, D.; STAMM, C.; SMITH, W. JIT implementation in small manufacturing firms. Production and Inventory Management Journal, p. 44-48, 1990.

KOH, H. C.; SIM, K. L.; KILLOUGH, L. N. The interaction effects of lean production manufacturing practices, compensation, and information systems on production costs: a recursive partitioning model. Advances in Management Accounting, v. 12, 2004.

LEAN ENTERPRISE INSTITUTE. Middle managers are biggest obstacle to lean enterprise. 2007. Disponível em: <www.lean.org>. Acesso em: 19 out. 2007.

LEAN Institute Brasil. 2007. Disponível em: <www.lean. org.br>. Acesso em 19 out. 2007.

LEWIS, M. Lean production and sustainable competitive advantage. International Journal of Operations \& Production Management, v. 20, n. 8, p. 155- 170, 2000.

LIAN, Y.; VAN LANDEGHEM, H. Analyzing the effects of Lean manufacturing using a value stream mappingbased simulation generator. International Journal of Production Research, v. 45, n. 13, p. 267-275, 2007.

LIKER, J. The Toyota way: 14 management principles from the world's greatest manufacturer. McGraw-Hill, 2004.

LILLRANK, P. The transfer of management innovations from Japan. Organization Studies, v. 16, n. 6, p. 971-989, 1995.

MANN, D. Creating a lean culture: tools to sustain lean conversions. New York: Productivity Press, 2005.

MONDEN, Y. Sistema Toyota de produção. São Paulo: IMAM, 1984.

NASA AMES RESEARCH CENTER NASA. Human Performance Research Group. NASA Task Load Index (TLX). Computerized version - v. 1.0. Moffet Field, California, 1986.

OHNO, T. Sistema Toyota de produção: além da produção em larga escala. Porto Alegre: Bookman, 1997.

RAAB, S. et al. Improving Papanicolau test quality and reducing medical errors by using Toyota Production
System methods. American Journal of Obstetrics and Gynecology, v. 194, p. 57-64, 2006.

ROTHER, M.; SHOOK, J. Aprendendo a enxergar: mapeando o fluxo de valor para agregar valor e eliminar o desperdício. São Paulo: Lean Institute Brasil, 1998.

SAURIN, T. A.; FERREIRA, C. F. The lean production impacts on working conditions: a case study of a harvester assembly line in Brazil. International Journal of Industrial Ergonomics, v. 39, n. 2, p. 403-412, 2009.

SHAH, R.; WARD, P. T. Lean manufacturing: context, practice bundles, and performance. Journal of Operations Management, v. 21, p. 129-149, 2003.

SHINGO, S. O Sistema Toyota de produção do ponto de vista da engenharia de produção. Porto Alegre: Bookman, 1996.

SMALEY, A. Criando o Sistema puxado nivelado. São Paulo: Lean Institute Brasil, 2004.

SOHAL, A.; EGGLESTON, A. Lean production: experience amongst Australian organizations. International Journal of Operations \& Production Management, v. 14, p. $135-150,1994$.

SORIANO-MEIER, H.; FORRESTER, P. A model for evaluating the degree of leanness of manufacturing firms. Integrated Manufacturing System, v. 13, n. 2, p. 104-110, 2002.

SPEAR, S.; BOWEN, H. Decoding the DNA of the Toyota Production System. Harvard Business Review, p. 97-106, 1999.

THE NORTHWEST Lean Networks - NWLEAN. 2007. Disponível em: <www.nwlean.net>. Acesso em: 20 nov. 2007.

UNITED STATES ENVIRONMENTAL PROTECTION AGENCY - EPA. The lean and environment toolkit. Version 1.0. 2006. EPA-100-K-06-003. Disponível em: <www.epa.gov/lean>. Acesso em: 28 nov. 2006.

WHITE, R. An empirical assessment of JIT in US manufacturers. Production and Inventory Management Journal, v. 2, p. 38-42, 1993.

WHITE, R. E.; PEARSON, J. N.; WILSON, J. R. JIT manufacturing: a survey of implementations in small and large U.S. manufacturers. Management Science, v. 45, n. 1, p. 1-15, 1999.

WOMACK, J.; JONES, D.; ROOS, D. The machine that changed the world. New York: Harper Perennial, 1991.

WOMACK, J; JONES, D. Lean thinking: banish waste and create wealth in your corporation. New York: Simon and Schuster, 1998. 